\title{
Secondary alveolar bone grafting: An outcome analysis
}

\author{
Ananth S Murthy MD, James A Lehman Jr MD FACS
}

\begin{abstract}
AS Murthy, JA Lehman Jr. Secondary alveolar bone grafting: An outcome analysis. Can J Plast Surg 2006;14(3):172-174.

OBJECTIVE: To review the outcome of secondary alveolar bone grafting in unilateral and bilateral cleft lip and palate.

DESIGN: A surgeon's experience, by retrospective chart review, of 70 consecutive patients at a tertiary care centre.

OUTCOME MEASURE: Periapical radiographs were taken at least six months after secondary alveolar bone grafting. The Enemark grading system was used to stratify graft-take.

RESULTS: In unilateral clefts, 33\% were level 1, 36\% were level 2, $20 \%$ were level 3 and $11 \%$ were level 4 . In bilateral clefts, $29 \%$ were level 1, 50\% were level 2, 14\% were level 3 and $7 \%$ were level 4 . There was no statistically significant difference between the level of take and the type of cleft. Complications encountered were infection $(n=3)$, fistula $(n=3)$, pain $(n=4)$ and bone graft exposure that led to failure $(n=2)$. Two patients required reoperation for bone grafting. CONCLUSIONS: The iliac crest is a good donor site with excellent results and minimal morbidity.
\end{abstract}

Key Words: Alveolar bone grafting; Cleft lip and palate; Enemark grading system; Iliac crest donor site; Secondary bone grafting

\section{Greffe osseuse alvéolaire secondaire : analyse de résultats}

BUT : L'étude avait pour but d'évaluer les résultats de la greffe osseuse alvéolaire secondaire chez des patients présentant une fente labiale et palatine unilatérale ou bilatérale.

PLAN D'ÉTUDE : L'étude consistait à évaluer l'expérience d'un chirurgien chevronné, auprès de 70 patients consécutifs, par un examen rétrospectif des dossiers, dans un établissement de soins tertiaires.

MESURES : Des radiographies périapicales ont été prises au moins six mois après la greffe osseuse alvéolaire secondaire. La prise de greffe a été classée selon l'échelle de cotation Enemark.

RÉSULTATS : Dans les cas de fente unilatérale, $33 \%$ des greffes étaient de niveau $1 ; 36 \%$, de niveau 2; $20 \%$, de niveau 3 et $11 \%$, de niveau 4 . Dans les cas de fente bilatérale, $29 \%$ des greffes étaient de niveau 1; $50 \%$, de niveau 2; $14 \%$, de niveau 3 et $7 \%$, de niveau 4 . Il n'y avait pas d'écart statistiquement significatif entre le niveau de prise de greffe et le type de fente. Les complications observées ont été l'infection $(n=3)$, la fistule $(n=3)$, la douleur $(n=4)$ et l'exposition de la greffe osseuse qui a abouti à l'échec de la prise $(\mathrm{n}=2)$. Deux patients ont dû être réopérés pour une greffe osseuse.

CONCLUSION : La crête iliaque constitue une bonne zone donneuse; elle produit d'excellents résultats et est accompagnée d'une très faible morbidité
Bone grafting of the cleft maxilla before eruption of the Bermanent cuspid has become an accepted part of the management of patients with clefts involving the maxillary alveolus. The reasons for performing a bone graft are to stabilize the maxillary segments, provide bony support for the teeth adjacent to the cleft, give additional support for the alar base and allow for the movement of the cuspid into the lateral incisor position. Typically, this procedure is performed at a stage of transitional dentition, when the canine root has not fully formed; this provides an osseous environment to support tooth eruption into the arch (1-3). Boyne and Sands (3) popularized the iliac crest as a donor site for alveolar bone grafting (4). Subsequently, Wolfe and Berkowitz (5) reported good ossification of bone grafts using the cranial bone. They cited ease of harvest and decreased donor site morbidity. Because of disappointing results found with cranial bone at the Children's Hospital Medical Center of Akron (Akron, Ohio, USA) the iliac crest has been chosen as the donor site.

To assess the success of the bone graft, several outcome measures have been suggested: eruption of cleft teeth, periodontal status (6), alveolar height (7-9), alar base support (10) and radiographic appearance of the bone (2). The present review measured the senior author's (JA Lehman) experience with secondary bone grafting using the iliac crest as a donor site. The outcome was based on bone graft survival as seen in periapical radiographs taken at least six months postoperatively.

\section{METHODS}

A retrospective review of 70 consecutive patients from 1993 to 1998 was performed. The iliac crest donor site was used in all patients. Variables evaluated included age, the type of cleft, graft donor site and complications. All secondary bone grafting was performed in conjunction with the eruption of the permanent canine, and maxillary expansion before bone grafting revealed an alveolar gap in all cases. The outcome was analyzed by periapical $\mathrm{x}$-rays of the cleft site to assess bone graft-take. The $\mathrm{x}$-rays were taken approximately six months after surgery. The Enemark grading system was used to assess the alveolar bone graft which was reflected as a percentage of septal bone height (Figure 1) (7). Once the results were tabulated, Student's $t$ test was used to assess statistical significance between the variables.

\section{RESULTS}

Using the Enemark system, all outcomes were classified into four levels: $100 \%$ to $75 \%$ take was graded as level $1 ; 75 \%$ to $50 \%$ take was graded as level 2; $50 \%$ to $25 \%$ take was graded as level 3; and $25 \%$ to $0 \%$ take was graded as level 4 . Twenty sites (29\%) were classified as level 1, 29 sites (41\%) were level 2, 12 sites (17\%) were level 3 and nine sites (13\%) were level 4 . In unilateral clefts, 33\% were level 1, 36\% were level 2, 20\% were level 3 and $11 \%$ were level 4 . In bilateral clefts, 29\% were level 1, 50\% were level 2, 14\% were level 3 and $7 \%$ were level 4 . There was no statistically significant difference between the level of take and the type of cleft. 
The complications encountered were infection $(n=3)$, fistula $(n=3)$, prolonged postoperative pain at donor site (more than two weeks) $(n=4)$ and bone graft exposure that led to failure $(\mathrm{n}=2)$. Two patients required reoperation for bone grafting after failure. There was no statistical correlation of complications with respect to age or the type of cleft.

\section{DISCUSSION}

Secondary bone grafting of the cleft maxilla before eruption of the permanent cuspids has become an accepted part of the management of patients with clefts involving the maxillary alveolus. The present review of 70 patients describes our success with autologous bone grafting using the iliac crest donor site. The quality of graft-take was determined radiographically using the Enemark system (7). Variables potentially influencing outcome included cleft type, graft donor site, age of grafting and complications. To evaluate our results, a retrospective study of alveolar grafts was performed.

It is clear that there is an increased incidence of recurrence in orocutaneous fistula when no bone graft is used. The reasons for performing an alveolar bone graft are to stabilize maxillary segments, to provide bony support for teeth adjacent to the cleft, to provide bone for the cuspid to be moved into the lateral incisor position and to provide support for the alar base $(1,3)$. Typically, this procedure is performed at a stage of transitional dentition, when the canine root has not fully formed. When performed at the appropriate time, this will provide an osseous environment that will support tooth eruption into the arch (2).

Historically, there has been a variety of donor sites used to fill the cleft. Tibial bone was the first bone graft used by Drachter (11) in 1914 in a palatoplasty. Boyne and Sands (3) popularized the iliac crest as a donor site for alveolar bone grafting (4). Now the choice of donor site is overwhelmingly the iliac crest, which is an ample source of cancellous bone, as reported in a recent survey by Murthy and Lehman (12). Albrektsson's in vitro studies (13) showed the superior survival of cancellous bone. The accepted rationale is that there is a rapid revascularization of the cancellous graft initially, which maintains greater volume over time. Cortical bone uses creeping substitution, which is a slow process, and without prompt revascularization, more bone graft loss may occur (14). Wolfe and Berkowitz (5) reported good ossification of bone grafts using cranial bone donor sites with ease of harvest and decreased donor site morbidity. Some authors reported unsatisfactory results comparing cranial bone and iliac crest, while some others reported similar results (15-18). As long as cancellous bone was used, there was no significant difference seen in the final outcome $(19,20)$.

\section{REFERENCES}

1. Abyholm FE, Bergland O, Semb G. Secondary bone grafting of alveolar clefts. A surgical/orthodontic treatment enabling a non-prosthodontic rehabilitation in cleft lip and palate patients. Scand J Plast Reconstr Surg 1981;15:127-40.

2. Bergland O, Semb G, Abyholm FE. Elimination of the residual alveolar cleft by secondary bone grafting and subsequent orthodontic treatment. Cleft Palate J 1986;23:175-205.

3. Boyne PJ, Sands NR. Secondary bone grafting of residual alveolar and palatal clefts. J Oral Surg 1972;30:87-92.

4. Sindet-Pedersen S, Enemark H. Reconstruction of alveolar clefts with mandibular or iliac crest bone graft: A comparative study. J Oral Maxillofac Surg 1990;48:554-8.

5. Wolfe SA, Berkowitz S. The use of cranial bone grafts in the closure of alveolar and anterior palatal clefts. Plast Reconstr Surg 1983;72:659-71.

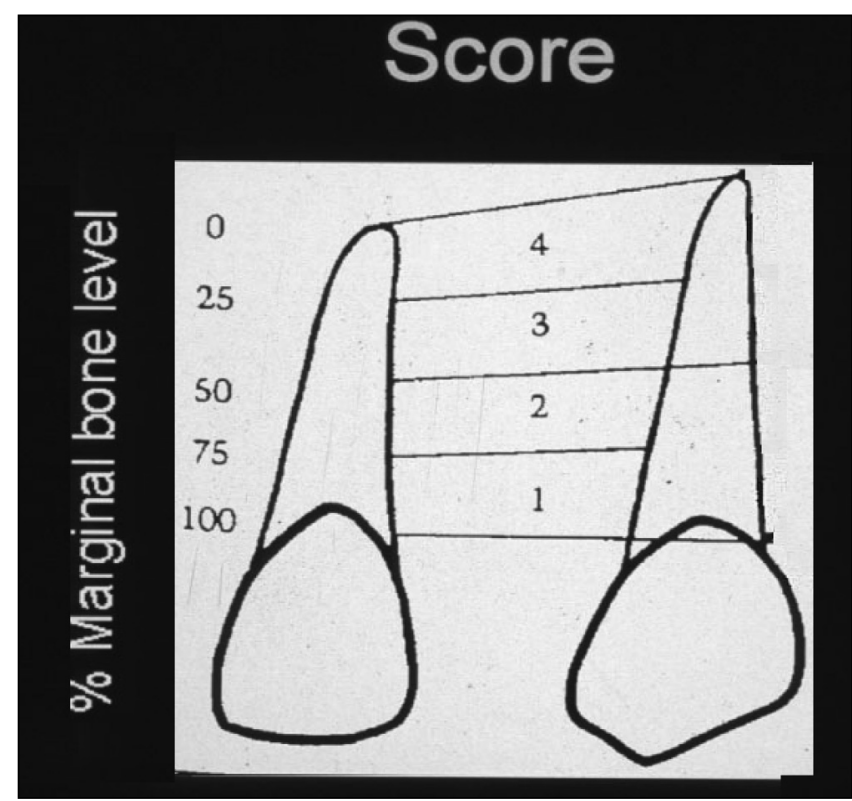

Figure 1) The Enemark grading system: $100 \%$ to $75 \%$ take was graded as level 1; 75\% to 50\% take was graded as level 2; 50\% to $25 \%$ take was graded as level 3; and $25 \%$ to $0 \%$ take was graded as level 4

Initially, we had a discouraging experience with cranial grafts. There was a 36\% failure rate, and this method was discontinued (unpublished data). The rest of the grafts were all from iliac crest donor sites. Laurie et al (21) reported increased morbidity with iliac donor sites. A high incidence of increased blood loss via the drain, delayed wound healing and moderate postoperative pain (average of six weeks) was reported (21). Our complications were not as severe, and included infection $(n=3)$, persistent fistula $(n=3)$, postoperative pain $(n=4)$ and bone graft exposure leading to failure $(n=2)$. When the complications were compared with regard to age (older or younger than 12 years of age), there was no significant difference seen. Similarly, there was no significant difference seen in complications with regard to the type of cleft (unilateral versus bilateral).

With respect to postoperative pain, a $22 \mathrm{G}$ catheter was left in the iliac crest, which was used to administer lidocaine for $24 \mathrm{~h}$. This alleviated the immediate postoperative pain in many cases and has been reported to be successful in pain relief (22). The catheter was removed the next day. Presently, there are commercially available lidocaine infusion pumps that aid in the administration of lidocaine in patients with postoperative pain.

6. Tan AE, Brogan WF, McComb HK, Henry PJ. Secondary alveolar bone grafting - five-year periodontal and radiographic evaluation in 100 consecutive cases. Cleft Palate Craniofac J 1996:33:513-8.

7. Enemark H, Sindet-Pedersen S, Bundgaard M. Long-term results after secondary bone grafting of alveolar clefts. J Oral Maxillofac Surg 1987;45:913-9.

8. Kindelan JD, Nashed RR, Bromige MR. Radiographic assessment of secondary autogenous alveolar bone grafting in cleft lip and palate patients. Cleft Palate Craniofac J 1997;34:195-8.

9. Witherow H, Cox S, Jones E, Carr R, Waterhouse N. A new scale to assess radiographic success of secondary alveolar bone grafts. Cleft Palate Craniofac J 2002;39:255-60.

10. Kokkinos PP, Ledoux WR, Kinnebrew MC, Weinberg R. Iliac apophyseal cartilage augmentation of the deficient piriform rim and 
maxilla in alveolar cleft grafting. Am J Orthod Dentofacial Orthop 1997;112:145-53.

11. Drachter R. Die gaumenspalte und deren operative behandlnng. Dtsch Z Chir 1914;131:1-89.

12. Murthy AS, Lehman JA. Evaluation of alveolar bone grafting: A survey of ACPA teams. Cleft Palate Craniofac J 2005;42:99-101.

13. Albrektsson T. Repair of bone grafts. A vital microscopic and histological investigation in the rabbit. Scand J Plast Reconstr Surg 1980;14:1-12.

14. Iino M, Ishii H, Sato J, Seto K. Histological evaluation of autogenous iliac particulate cancellous bone and marrow grafted to alveolar clefts - A preliminary report of five young adult cases. Cleft Palate Craniofac J 2000;37:55-60.

15. Cohen M, Figueroa AA, Haviv Y, Schafer ME, Aduss H. Iliac versus cranial bone for secondary grafting of residual alveolar clefts. Plast Reconstr Surg 1991;87:423-7.

16. Cohen M, Polley JW, Figueroa AA. Secondary (intermediate) alveolar bone grafting. Clin Plast Surg 1993;20:691-705.
17. Harsha BC, Turvey TA, Powers SK. Use of autogenous cranial bone grafts in maxillofacial surgery: A preliminary report. J Oral Maxillofac Surg 1986;44:11-5.

18. Kortebein MJ, Nelson CL, Sadove AM. Retrospective analysis of 135 secondary alveolar cleft grafts using iliac or calvarial bone. J Oral Maxillofac Surg 1991;49:493-8.

19. Denny AD, Talisman R, Bonawitz SC. Secondary alveolar bone grafting using milled cranial bone graft: A retrospective study of a consecutive series of 100 patients. Cleft Palate Craniofac J 1999;36:144-53.

20. LaRossa D, Buchman S, Rothkopf DM, Mayro R, Randall P. A comparison of iliac and cranial bone in secondary grafting of alveolar clefts. Plast Reconstr Surg 1995;96:789-97.

21. Laurie SW, Kaban LB, Mulliken JB, Murray JE. Donor-site morbidity after harvesting rib and iliac bone. Plast Reconstr Surg 1984;73:933-8.

22. Hoard MA, Bill TJ, Campbell RL. Reduction in morbidity after iliac crest bone harvesting: The concept of preemptive analgesia. J Craniofac Surg 1998;9:448-51. 